\title{
Active Surveillance for Patients with Micro Papillary Thyroid Cancer in UK
}

\author{
Pavithran Maniam ${ }^{1}$, Noah Harding ${ }^{2}$, Lucy Li ${ }^{3}$, Richard Adamson², Ashley Hay ${ }^{4}$, and Iain \\ Nixon $^{4}$ \\ ${ }^{1}$ Royal Infirmary of Edinburgh \\ ${ }^{2}$ Department of Otorhinolaryngology Head and Neck Surgery, NHS Lothian, Edinburgh, \\ UK \\ ${ }^{3}$ Queen Elizabeth University Hospital \\ ${ }^{4}$ NHS Lothian
}

February 7, 2022

\begin{abstract}
Background The incidence of thyroid cancer is increasing globally due to the increase in detection of subclinical, low volume papillary thyroid microcarcinomas (PTMC) $(<1 \mathrm{~cm})$. Several international groups have recommended an active surveillance approach for this low-risk disease. In contrast to many other countries, the UK's approach to thyroid nodules is to avoid detection of incidental lesions where appropriate. Objective This study aims to establish the proportion of patients with thyroid cancer in the UK that would benefit from active surveillance. Design, participants, and outcome measures: Individuals with PTMC in NHS Lothian from 2009-2020 were reviewed from a local thyroid cancer database. The mode of detection of PTMC and proportion of patients who might benefit from active surveillance were established. Results From 651 individuals with differentiated thyroid cancer managed over 12-year period, 185 individuals with PTMC were identified (28.4\%). The majority of PTMC 151/185 (81.6\%) were either diagnosed post-operatively following thyroidectomy for benign disease or with nodal disease. Only 24 individuals with PTMC were identified following palpable thyroid nodule, incidental finding on imaging and surveillance screening. Therefore, when the indication for surgery was considered, only 24/651 (3.7\%) patients were identified pre-operatively and would therefore be realistic candidates for active surveillance. Conclusion Less than $4 \%$ of patients with thyroid cancer in the UK would be appropriate for active surveillance. Rather than developing programs to deal with this minority of patients, focus should be maintained on minimizing detection of these low-risk cases.
\end{abstract}

\section{Hosted file}

Manuscript.docx available at https://authorea.com/users/459368/articles/555652-activesurveillance-for-patients-with-micro-papillary-thyroid-cancer-in-uk

Hosted file

Table 1.docx available at https://authorea.com/users/459368/articles/555652-activesurveillance-for-patients-with-micro-papillary-thyroid-cancer-in-uk

\section{Hosted file}

Table 2.docx available at https://authorea.com/users/459368/articles/555652-activesurveillance-for-patients-with-micro-papillary-thyroid-cancer-in-uk 